\title{
Intellectual systems for the land-and-property complexes as the subject of investment-and-construction activity
}

\author{
Nadezhda Samoylova ${ }^{1,2, *}$ \\ ${ }^{1}$ Moscow State University of Civil Engineering (National Research University) (MGSU), 26, \\ Yaroslavskoye shosse, 129337, Moscow, Russia \\ ${ }^{2}$ Russian Academy of Architecture and Construction Sciences (RAACS), 24, Bolshaya Dmitrovka \\ street, 107031, Moscow, Russia
}

\begin{abstract}
The article presents an innovative proposal to improve the management of the land and property complex facilities. The simulation modeling is based on the developed formulas for accounting and determining the most persistent functions of facilities in the Spatial organization model of urban-planning formations (Yu.V. Alekseeva and N.A. Samoylova). In particular, the formula contains mathematical expressions for the conditions for determining the most persistent private function for various types of facilities: existing buildings and structures, ground level territory, above-ground and underground territories (urbanplanning and quasi urban-planning). Such a system is applicable at all levels of control: from local to national and even international one, all types of urban-planning transformation (from new development of the territory to renovation, revitalization, etc.). To create intelligent systems in the field of urban-planning, it is especially important to use such a method in the information program (decision support system) that the effect of investment and construction activities is laid at the pre-project stage of planning the life cycle management of land and property complexes. One of the tools for this is the formulas developed in the framework of fundamental scientific research carried of the Russian Academy of Architecture and Construction Sciences (RAACS) and the Central Institute for Research and Design of the Ministry of Construction and Housing and Communal Services of the Russian Federation.
\end{abstract}

\section{Introduction}

The spatial organization model of urban-planning formations (a model of structural organization in urban-planning formations) is a systematic approach to the formation of urban-planning space, based on the division of the general system into components, the allocation of levels of interaction of subsystems in it, the establishment of levels of interaction of factors in each subsystem and their consideration for urban-planning [1, 2, 3].

The model, which includes four interconnected and interacting spatial objects,

\footnotetext{
* Corresponding author: nad1s@yandex.ru
} 
determines the order of transformation and intervention in nature. On the basis of the model and methodology of the spatial organization of settlements, a set of works was performed to reconstruct and develop the territories of the existing five-storied building system in Moscow and other cities of Russia, to form new building system where underground and above-ground territories were used. The regularities of planning factors having impact on the interconnection of spatial facilities in urban-development and urban-planning of settlements were established, which was reflected in monographies [2, 4] and articles [3, 59].

However, the Model and Methodology does not yet provide for the creation of a systematized information base for identification, accounting and assessment of construction resources in settlements and adjacent territories, as well as urban-planning regulation of the environment. At the same time, the Spatial organization model of urban-planning formations contains the theoretical foundations for the development of information modeling of urban-planning regulation of the parameters of the environment quality.

To use the Model in the information environment of programming and formalize description of facilities I - IV (I - ground and underground buildings, structures, II - ground level territory), III - ground - natural complex), IV - above-ground areas) and their functional processes, functions and factors of N.A. Samoylova $[1,10]$ in addition to this model introduced unified individual designations, their parameters and indices (Figures 15).

The unified designations of the spatial organization model of urban-planning formations allow to perform the parameterization of facilities I-IV in settlements and the adjacent territories with the use of modern information technologies, i.e. to determine characteristic functional processes for these facilities, the most persistent functions for facilities I-IV (main and auxiliary functions of facilities, as well as their corresponding particulate functions) (Figures 2-5). 


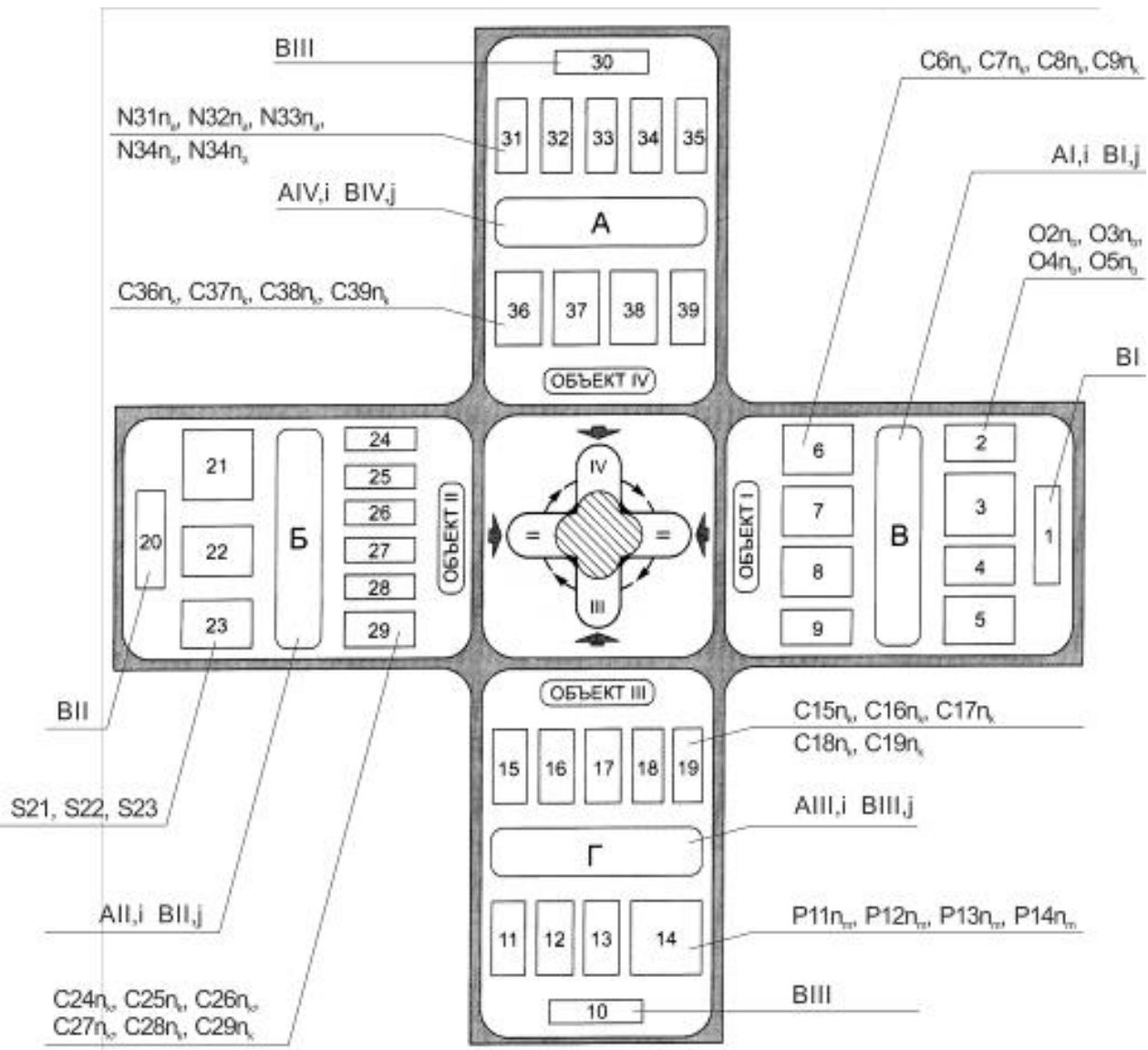

Fig. 1. A model of the spatial organization of urban-planning formations with unified individual designations, their parameters and indices [10].

Where: Facilities: I (ground and underground buildings, structures), II (ground level territory), III (ground - natural complex), IV (above-ground territories). Main and auxiliary functions: "BI" is designated instead of "1" at the facility I, "BII" - instead of " 10 " at the facility II, "BIII" - instead of " 20 " at the facility III, "BIV" - instead of " 30 " at the facility IV. Functional processes: "AI,i" with their corresponding particulate functions "BI,j" is designated instead of "B" at the facility I, "AII,i", "BII,j" - instead of "B" at the facility II, "AIII,i", "BIII,j" - instead of " $\Gamma$ " at the facility III, "AIV,i", "BIV,j" - instead of "A" at the facility IV. Types of buildings and structures (2-5) at the facility I - "O" with the corresponding indices "O2nb", "O3nb", "O4nb", "O5nb". Territory types at ground level (21-23) at the facility II - "S" with the corresponding indices "S21nz", "S22 nz", "S23 nz". Types of natural complex (11-14) at the facility III are "P" with the corresponding indices "P11nm", "P12nm", "P13nm", "P14nm". Types of above-ground territory (3135 ) at the facility IV are "N" with the corresponding indexes "N31na", "N32na", "N33na", "N34na", "N35na". Factors 6 - 9 at the facility I - marked "C" with the corresponding indices "C6nk", "C7nk", "C8nk" and "C9nk", factors $24-29$ at the facility II - "C" with the corresponding indices "C24nk", "C25nk", "C26nk", "C27nk", "C28nk", "C29”, factors $15-19$ at the facility III - "C" with the corresponding indices "C15nk", "C16nk", "C17nk", "C18nk", "C19nk", factors 36 - 39 at the facility IV - "C" with the corresponding indices “C36nk", “C37nk”, “C38nk”, “C39nk”, “C40nk”. 


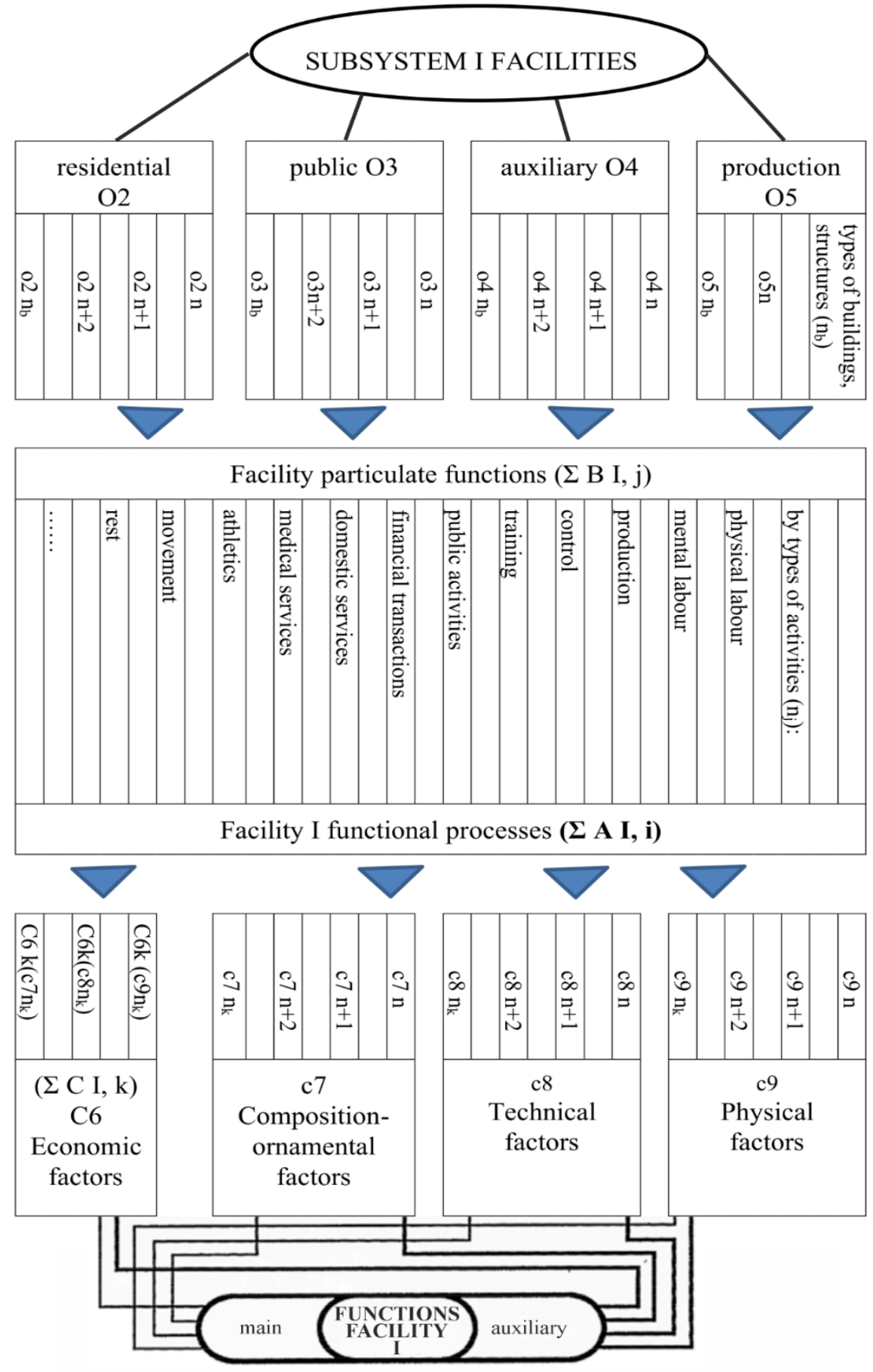

Fig. 2. Subsystem I Facilities. 


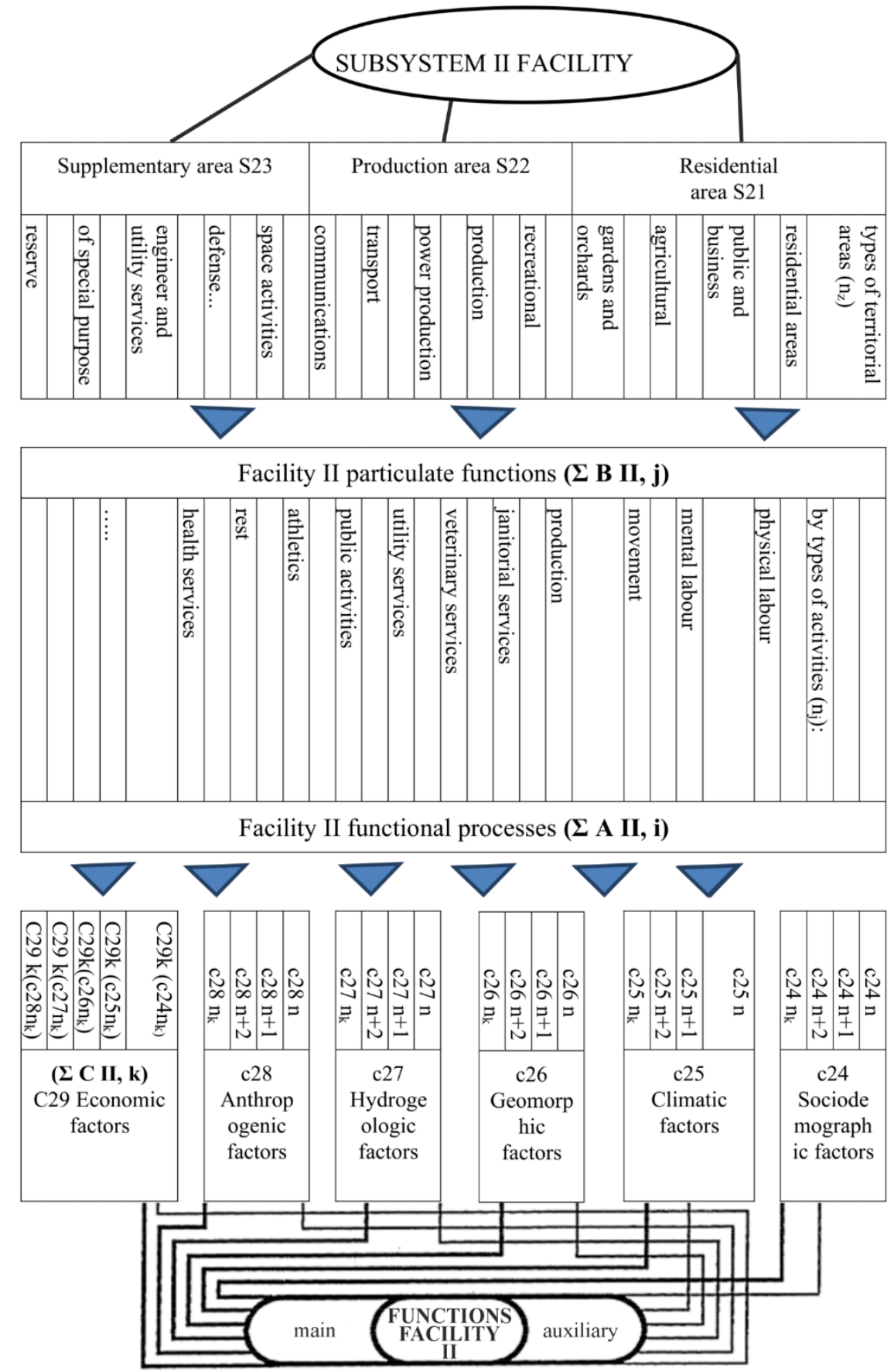

Fig. 3. Subsystem II Facilities. 


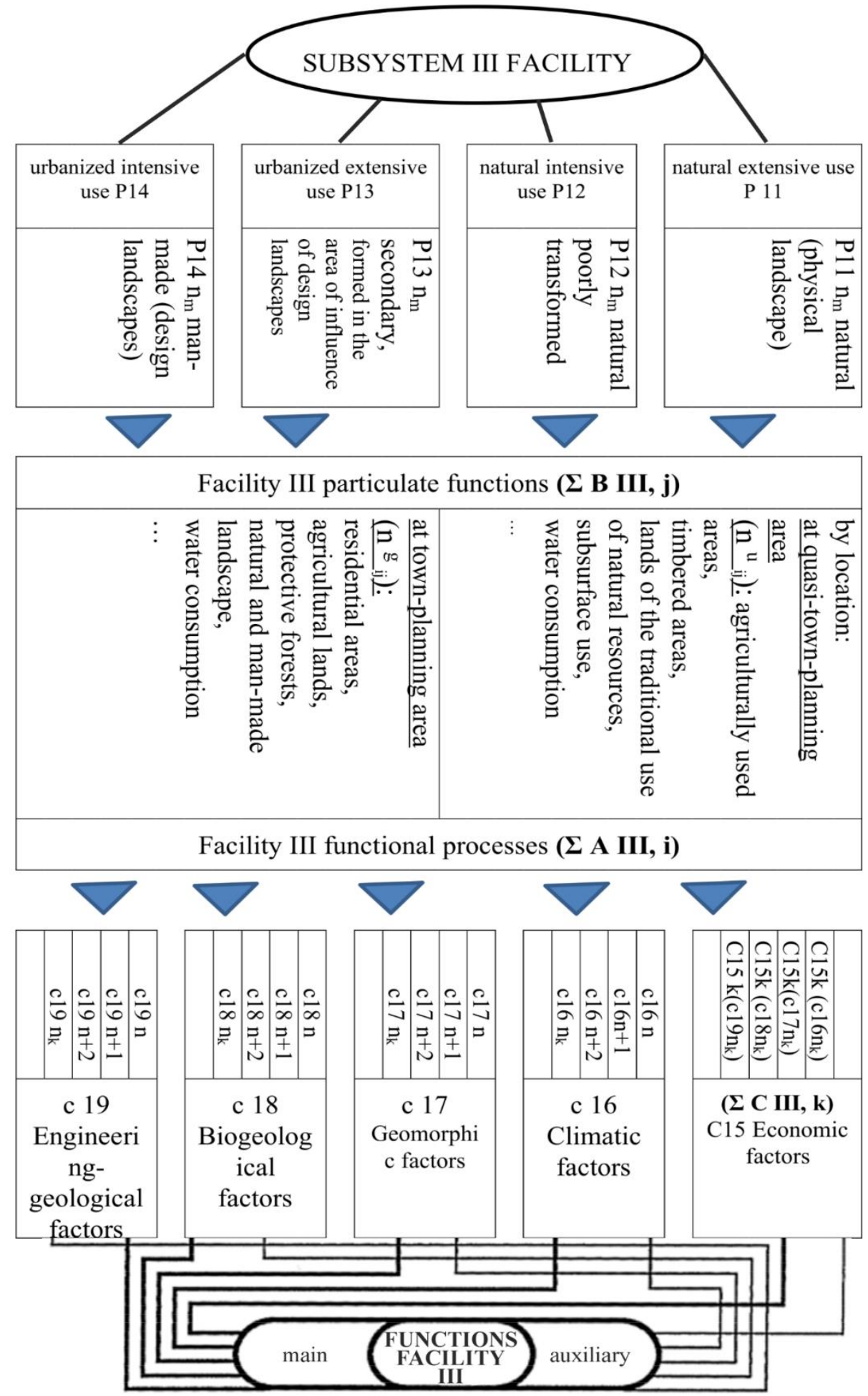

Fig. 4. Subsystem III Facilities. 

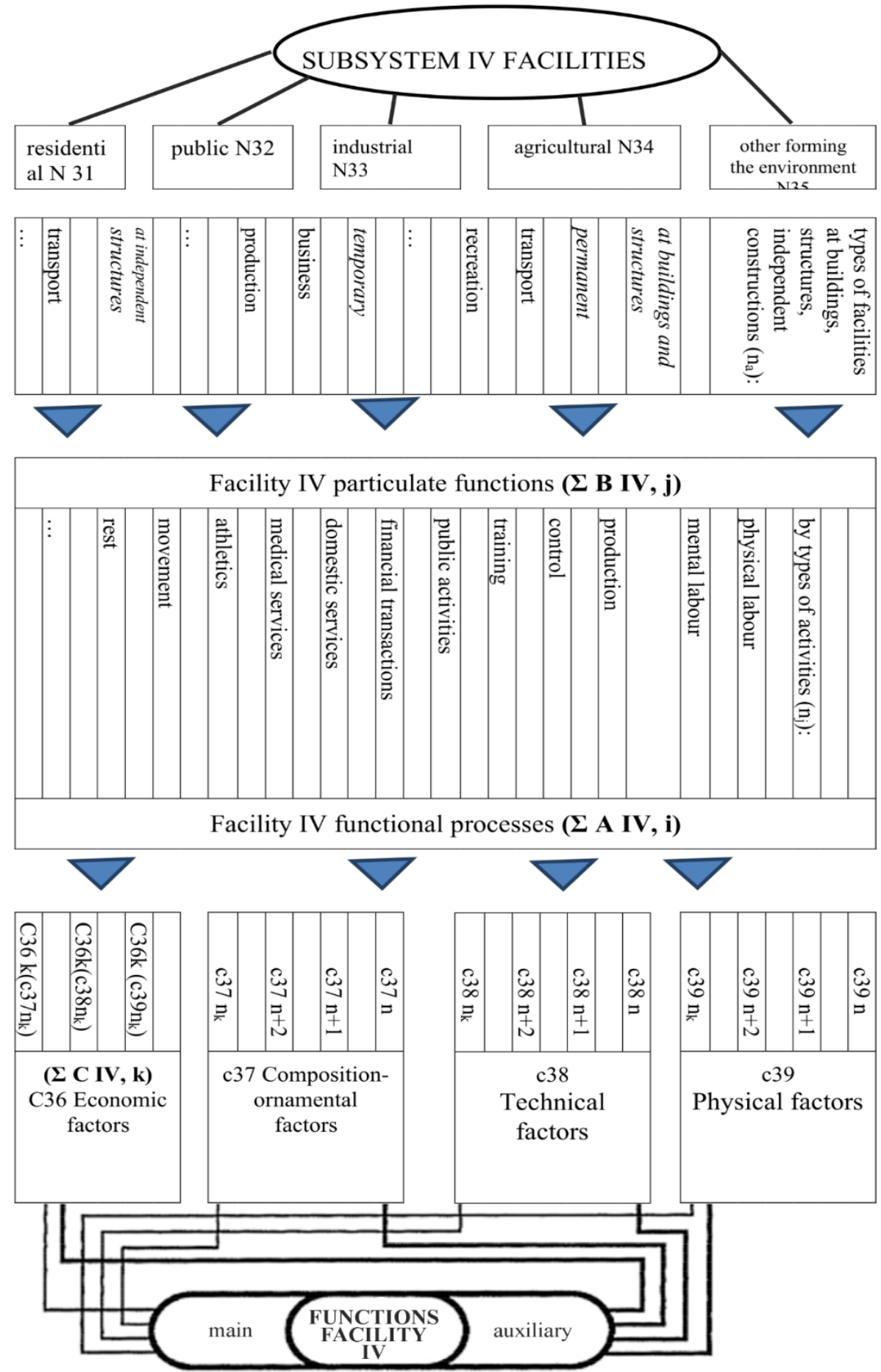

Fig. 5. Subsystem IV Facilities. 


\section{Objectives}

The main purpose of this research is fundamental simulation modeling, in particular, accounting and determining the most persistent functions of objects in the Spatial organization model of urban-planning formations, taking into account the spacial and temporal nature of changes in the territory, in urban-planning and quasi urban-planning area. N o t e - Quasi urban-planning area is an area in respect of which a decision was made on its urban-planning use, or a territory that has a high potential for urban-planning development due to its proximity to an already developed urban-planning area [11].

The sequence of determining the most persistent urban-planning (all aesthetic) particulate functions $\mathrm{Bn}, \mathrm{j}$ consists in grouping the signs of factors of urban-planning formations ( $\mathrm{Cnk}$ ) into differentiated, classification and alternative ones, compared to the signs of factors by levels of territorial coverage: local, regional, etc.

Within the framework of fundamental scientific research (NIOKTR) RAACS and the Ministry of Construction, Housing and Utilities of the Russian Federation (reg. No. NIOKTR AAAA-A19-119060490065-9) [10] in continuation of the previously performed research (reg. No. NIOKTR AAAA-A16-116041410183-6) [1] mathematical expressions of the conditions for determining the most persistent particulate function $(\mathrm{Bn}, \mathrm{j})$ of facilities I-IV were concluded, taking into account the level of territorial coverage.

\section{Results}

In accordance with the Model, when considering the components in each facility I - IV, the main and auxiliary functions of the facilities are distinguished, as well as the corresponding particulate functions $(\mathrm{Bn}, \mathrm{j}$ ) (Figures 2-5). One of the important stages in the determination of the most persistent urban-planning (all aesthetic) particulate functions $\mathrm{Bn}, \mathrm{j}$ is to identify the most persistent particulate function (Bn,j) of facilities I - IV (formulas 1, 2).

The most persistent private functions $(\mathrm{Bn}, \mathrm{j})$ can be identified at one or more facilities I - IV, formula (1):

$$
\text { B n, j= B I,j \O I,nb U B II,j \S II,nz U B III,j \P III,nm U B IV,j \N IV, na }
$$

where: B I, j - the most persistent function of the facility I;

$\mathrm{OI}, \mathrm{nb}$ - types of ground and underground buildings and structures (b) of facility I,

B II, $\mathrm{j}$ - the most persistent function of the facility II;

S II,Z - types of territorial zones (z) of facility II,

B III, $\mathrm{j}$ - the most persistent function of the facility III;

P III, nm - types of landscape (m) of facility III,

B IV, $\mathrm{j}$ - the most persistent function of the facility IV;

NIV,na - types of facilities at buildings, structures, and independent structures (a) of facility IV.

I - mathematical symbol, which means a set of elements belonging, for example, to BI, $\mathrm{j}$, but not belonging to $\mathrm{OI}, \mathrm{n}_{\mathrm{b}}$.

$\mathrm{U}$ is a mathematical symbol of union, meaning a set of elements belonging to one or more facilities;

In facilities I, II, III or IV, there is the most persistent function Bn,j, which belongs to at least one of the levels of the territorial coverage of the urban-planning project, formula (2):

$$
\exists B \mathrm{n}, \mathrm{j}(\mathrm{I}, \mathrm{II}, \mathrm{III}, \mathrm{IV}) \in\{\mathrm{W}, \mathrm{M}, \mathrm{G}, \mathrm{R}, \mathrm{L}\}
$$


where: $\exists$ is a mathematical symbol, which means that there is at least one particulate function $\mathrm{Bn}, \mathrm{j}$ for one of the facilities, for which the expression of belonging $(\epsilon)$ to the level of territorial coverage will be true: W - global level,

$\mathrm{M}$ - cross-country level,

$\mathrm{G}$ - national level,

$\mathrm{R}$ - regional,

L - local.

The ratio of the functional process and the particulate functions of the facility I - IV is such that the search for the most persistent feature is carried out in the functional process or its particulate function, in the whole set of specific types of buildings and structures, types of territorial areas, types of landscapes, types of above-ground territories belonging to certain facilities I - IV, formula (3):

$$
\text { An,i / B n,j } \rightarrow \text { n (a,b,m,z) } \forall(\text { SII,nz U PIII,nm U OI,nb U NIV,na) }
$$

where: An,i - functional process of one of facilities I - IV

$\mathrm{B} \mathrm{n}, \mathrm{j}$ - the most persistent function of the facilities I - IV,

$\rightarrow$ mathematical function (expression) "everywhere",

$\forall$ - mathematical symbol meaning "true for everything"

$\mathrm{U}$ - mathematical symbol of union, meaning a set of elements belonging to one or more facilities;

$\mathrm{n}$ is the index of the ordinal designation of a specific type (kind) of facilities I - IV,

a - types of facilities at buildings, structures and independent constructions,

$\mathrm{b}$ - types of ground and underground buildings and structures,

$\mathrm{m}$ - types of landscapes,

$\mathrm{z}$ - types of territorial areas,

OI,nb - types of ground and underground buildings and structures (b) of facility I,

SII,nz - types of territorial zones (z) of facility II,

PIII,nm - types of landscapes (m) of facility III,

NIV,na - types of facilities at buildings, structures, and independent structures (a) of facility IV.

Comparison of $\mathrm{Bn}, \mathrm{j}$ is carried out first at one of the levels of the project territorial coverage, and then with the nearest levels, and so on until significant indicators that record the most persistent particulate function of the subsystem I - IV facility is determined $(\mathrm{Bn}, \mathrm{j})$.

4 Conclusions

It becomes obvious that the roles of stakeholders in urban-planning are changing [12, 13], and urban-planning regulation is transforming [14], based on information modeling of the quality and safety of the environment [15].

The conducted study presents the relationship between urban-planning and information regulation of the quality and safety of the environment. The study was conducted in line with the increasing need to find a compromise between all stakeholders in urban-planning activities in relation to systems of land and property complexes as a subject of investment and construction activities.

The study is based on the use of the STT software complex, an interactive analytical environment for group support for the development of managerial decisions and a computer program "Decision Support System" (DSS) for urban-planning regulation of the quality and safety of the environment by searching for an urban-planning compromise when forecasting and planning various urban-planning transformations of the territory of any urban-planning types and the assessment of the results of urban-planning for various types of urbanplanning documents [16].

The study conducted will contribute to the establishment of new urban-planning opportunities for improving the quality and safety of the environment with the use of 
information modeling of the environment with the use of information and communication technologies. Scientific research can serve as a basis for updating the modern system of urban-planning regulation and is addressed both to urban planners, professionals and to government authorities of all levels acting as decision-makers in the field of urbanplanning, as well as individuals and legal entities which are expanding their role in urbanplanning activities.

The applied implementation of the given scientific foundations will be the formation of the software package promising modules for rating assessment and selection of efficient urban-planning solutions as per unequal criteria in different measurement scales in different areas of urban-planning impact in real-time mode.

It appears that the spatial organization model of urban-planning formations and schematic and parametric collocations and relationships can be used as a basis for creating a systematic information base for identifying and accounting for resources of the territory, as well as urban-planning regulation of the environment quality parameters with the use of information modeling.

\section{Acknowledgments}

The author would like to thank the RAACS and the Ministry of Construction, Housing and Utilities of the Russian Federation for financial support and encouragement Alekseev Yu.V. from MGSU.

\section{References}

1. N.A. Samoylova, Conceptual foundations of urban-planning and the organization of urban-planning activities when using the territories of the coal basins of Russia (NIOKTR AAAA-A16-116041410183-6, Moscow, 2016)

2. Y.V. Alekseev, Urban-planning bases for the development and reconstruction of residential buildings (ASV Publ, Moscow, 2009)

3. Yu.V. Alekseev, Int.-Conf. (Sustainable development of territories) (NRU MGSU, Moscow, 2019)

4. Yu.V. Alekseev, G.Yu. Somov, Urban-planning of residential areas and communities (ASV Publ, Moscow, 2010)

5. Yu.V. Alekseev, V.L. Belyaev, VESTNIK MGSU 2, 6-10 (2012)

6. O. Gamayunova, M. Petrichenko, A Mottaeva, Journal of Physics: Conference Series 1614, 012066 (2020) doi:10.1088/1742-6596/1614/1/012066

7. Yu.V. Alekseev, Urban-planning 1(53), 22-28 (2018)

8. Yu.V. Alekseev, E3s Web Conf. ITESE-2019 135 (2019)

9. Yu.V. Alekseev, Architecture and Construction of Russia 1, 22-31 (2020)

10. N.A. Samoylova, Natural and Technogenic Risks. Safety of Structures 3(40), 61-65 (2019)

11. N.A. Samoylova, Urban-planning regulation of the parameters of the quality of the environment with the use of innovative technologies. Scientific foundations of urbanplanning regulation of the environment with the use of information modeling Research report chapter 4.3.6. / 4.3.11 Plan of fundamental scientific research of the RAACS and the Ministry of Construction, Housing and Utilities of the Russian Federation for 2018 - 2019 (Moscow: NIOKTR AAAA-A19-119060490065-9) p 236

12. N.A. Samoylova, O.A. Zhirkov, S.V. Belkin, Communicology 8(2), 53-79 (2020) 
13. N.A. Samoylova, Yu.V. Alekseev 18th IFAC Conf. TECIS 2018 (Baku) IFACPapersOnLine 51(30), 780-785 (2018)

14. N A Samoylova, Ecology of Urban areas 3, 95-106 (2019)

15. N.A. Samoylova, Urban planning and Urban development of living environment using information modeling Proc. Symp. RAACS (ASV Publ., Moscow, 2019)

16. N.A. Samoylova, O.A. Zhirkov, Certificate of state registration of the computer program "Decision Support System" (DSS) for evaluating decision options by stakeholders in urban-planning activities for various urban-planning types of areas (at the pre-design stage of urban-planning transformation of areas) No 2019667346 (2019) 